\title{
Rethinking how risk aversion and impatience are linked with cognitive ability: Experimental findings from agricultural students and farmers
}

\author{
Sven Grüner \\ Faculty of Natural Sciences III \\ Institute of Agricultural and Nutritional Sciences \\ Martin Luther University Halle-Wittenberg \\ Contact: sven.gruener@landw.uni-halle.de
}

First version upload date: 25.02 .2021

This version upload date: 25.02 .2021

\begin{abstract}
$\underline{\text { Abstract }}$
Dohmen et al. (2010) describe in their paper, which has been published in the American Economic Review, that risk aversion and impatience are negatively related to cognitive ability. This topic is important because controlling for cognitive ability might be necessary if someone is interested in the link of risk preferences or time preferences to real-world outcomes. We re-examine their key results by conducting an experimental study using two subject pools (agricultural students and farmers) and three levels of monetary incentives. Similar to Dohmen et al. (2010), our study finds the above-described negative correlations. However, the strength of the association is smaller and the $\mathrm{p}$-values are quite large.
\end{abstract}

$\underline{\mathrm{JEL}}$

C91, D91

$\underline{\text { Keywords }}$

Risk aversion; impatience; cognitive abilities; replication 


\section{Introduction}

Human decision making rests on preferences and cognitive abilities to process information. Cognitive abilities have been addressed, for example, in the realm of inflation expectations (D'Acunto et al. 2019), numerical abilities in kindergarten children (Passolunghi et al. 2015), environmental awareness (Salahodjaev 2018), and Bolivian forager-farmers with limited schooling (Gurven et al. 2017). Among the preferences that are often incorporated in economic models are risk attitude and time preferences (Falk et al. 2018). They are also relevant in farmers' decision making. Crop diversification strategies and insurance purchasing decisions to cope with climate risks are associated with risk preferences (Dalhaus et al. 2018; Asravor 2019), whereas the propensity to undertake investment in environmental preservation and other agricultural investments are related to time preferences (Di Falco et al. 2019; Hermann and Musshoff 2016). But how are cognitive related to risk and time preferences?

Dohmen et al. (2010) argue that it is common in economic models to assume that cognitive ability is independent to both risk aversion and impatience. In contrast, they find in their study a positive association between cognitive abilities and patience and a negative relationship between cognitive abilities and risk aversion. Both findings are robust to variation in socio-demographic variables such as age and gender. Later, Dohmen et al. (2018) stress in their literature review, that the negative correlation of cognitive ability and risk aversion in lottery choices is prevalent in the domain of gains, whereas in the domain of potential losses the association is positive. These findings are important if someone is interested in the associations between risk aversion or impatience and real-world outcomes-controlling for individuals' cognitive abilities might be necessary.

This paper aims at experimentally re-analyzing the robustness of the above-described relationships between risk aversion and impatience with cognitive ability. The recent replication crisis led to an increased attention of researchers to replication studies (Christensen and Miguel 2018; Dreber and Johannesson 2019). We do so by considering different monetary incentive levels in our experiments - ranging from very low to relatively high. Real-life situations differ in the amount of monetary stakes involved. There is experimental evidence that the size of the monetary incentives matters. For example, in contrast to rational choice predictions, relatively low monetary incentives might crowd out subjects' intrinsic motivation. Another example is the stake size effect, i.e., the phenomenon that increasing the monetary stakes goes hand in hand with the individuals' tendency to be more risk averse. Moreover, we recruit both agricultural students and farmers. Most experimental lab studies are conducted with university students (Guala 2005, Henrich et al. 2010, Fréchette 2015). They are easy to recruit and have low opportunity costs. However, the external validity of using students is at question if we are interested in the behavior of farmers, who are on average older than students and have more working experience.

Risk aversion, impatience, and cognitive abilities cannot be observed directly (i.e., latent constructs) but must be measured. Risk aversion is measured with the help of the procedure according to Holt and Laury (2002). Broadly speaking, subjects decide between two options, where one represents a safer choice (but with lower payoffs) and the other one is riskier (but offers the chance to gain higher payoffs). We adopt Laury et al. (2012)'s procedure to elicit discount rates (i.e., impatience). The basic idea is to put subjects in a trade-off between earning a given amount 
of money sooner and earning the same amount of money later but with a higher probability. Cognitive abilities are measured with the help of the cognitive reflection test (CRT), which was originally introduced by Frederick (2005). Subjects are shown questions where a quick answer is often wrong (i.e., intuitive thinking), but rethinking the answer often leads to the identification of the correct answer. It has been shown that the results of this test are highly correlated with cognitive abilities (Oechssler et al. 2009, Bosch-Rosa et al 2018). Since Frederick's CRT might be well known among the subjects due to its popularity in use, we use reworded but also new item questions from various sources (Frederick 2005; Baron et al 2015; Thomson and Oppenheimer 2016).

The rest of the paper is organized as follows. Section 2 presents the experimental design. After describing the subjects (Section 3), we describe the experimental findings in Section 4. Section 5 concludes.

\section{Experimental design}

In the following, we describe the design of the experiments. ${ }^{1}$ Both agricultural students and farmers were randomly assigned to one of three scenarios. The scenarios differed in the size of stakes, ranging from very low to relatively high. The basic idea was to consider the fact that real-life situations differ in the size of its monetary stakes. There is a wide range from doing things due to intrinsic motivation to doing business just for money (Frey 1997). Overall, a total of $10 \%$ of the subjects were rewarded with monetary incentives beyond the participation fee of $€ 5$ and $€ 20$ for students and farmers, respectively, for completing the experiment.

\subsection{Measuring risk attitude: Holt and Laury (2002)}

In the risk elicitation task according to Holt and Laury (2002), subjects choose between the lottery pairs $A$ and $B$ for 10 rows. For example, in decision situation 1 subjects have a $1 / 10$ probability to gain $€ 2.00$ and a $9 / 10$ probability to gain $€ 1.60$ in option $A$ and a $1 / 10$ probability to gain $€ 3.85$ and a $9 / 10$ probability to gain $€ 0.10$ in option $B$. The gap between the better and worse outcome in option A is relatively small and in option B relatively large. Thus, option A is also denoted as "safer option" and option B as "riskier option". Risk aversion is measured in terms of the number of safer choices A. Risk seeking means 0-3 A-choices, 4 A-choices reflect risk neutrality, 5-9 (10) Achoices are associated with risk aversion.

\footnotetext{
1 This study has been approved by the German Association for Experimental Economic Research e.V. (No. $1 \mathrm{VjNTvM} 3)$.
} 
Table 1: Lottery-choice decisions and risk aversion classification (Scenario 1) ${ }^{(a)}$

\begin{tabular}{|l|l|l|l|l|l|l|}
\hline Row & Option $\mathbf{A}$ & Option B & $\begin{array}{l}\text { Expected } \\
\text { payoff } \\
\text { difference }\end{array}$ & $\begin{array}{l}\text { Number of } \\
\text { "safer" A } \\
\text { choices }\end{array}$ & $\begin{array}{l}\text { Range of relative } \\
\text { risk aversion }\end{array}$ (b) & $\begin{array}{l}\text { Risk preference } \\
\text { classification }\end{array}$ \\
\hline 1 & $\begin{array}{l}1 / 10 \text { of } € 2.00, \\
9 / 10 \text { of } € 1.60\end{array}$ & $\begin{array}{l}1 / 10 \text { of } € 3.85, \\
9 / 10 \text { of } € 0.10\end{array}$ & $€ 1.17$ & $0-1$ & $\mathrm{r}<-0.95$ & highly risk loving \\
\hline 2 & $\begin{array}{l}2 / 10 \text { of } € 2.00, \\
8 / 10 \text { of } € 1.60\end{array}$ & $\begin{array}{l}2 / 10 \text { of } € 3.85, \\
8 / 10 \text { of } € 0.10\end{array}$ & $€ 0.83$ & 2 & $-0.95<\mathrm{r}<-0.49$ & very risk loving \\
\hline 3 & $\begin{array}{l}3 / 10 \text { of } € 2.00, \\
7 / 10 \text { of } € 1.60\end{array}$ & $\begin{array}{l}3 / 10 \text { of } € 3.85, \\
7 / 10 \text { of } € 0.10\end{array}$ & $€ 0.50$ & 3 & $-0.49<\mathrm{r}<-0.15$ & risk loving \\
\hline 4 & $\begin{array}{l}4 / 10 \text { of } € 2.00, \\
6 / 10 \text { of } € 1.60\end{array}$ & $\begin{array}{l}4 / 10 \text { of } € 3.85, \\
6 / 10 \text { of } € 0.10\end{array}$ & $€ 0.16$ & 4 & $-0.15<\mathrm{r}<0.15$ & risk neutral \\
\hline 5 & $\begin{array}{l}5 / 10 \text { of } € 2.00, \\
5 / 10 \text { of } € 1.60\end{array}$ & $\begin{array}{l}5 / 10 \text { of } € 3.85, \\
5 / 10 \text { of } € 0.10\end{array}$ & $-€ 0.18$ & 5 & $0.15<\mathrm{r}<0.41$ & slightly risk \\
averse
\end{tabular}

(a) Subjects were only shown the first three columns.

(b) Assuming $\mathrm{U}(\mathrm{x})=\mathrm{x}^{1-\mathrm{r}} /(1-\mathrm{r})$, i.e., constant relative risk aversion.

The payoffs of the scenarios read as follows:

$\mathrm{A}(€ 2.00, € 1.60)$ \& $\mathrm{B}(€ 3.85, € 0.10)$, if scenario 1

$\mathrm{A}(€ 20.00, € 16.00) \& \mathrm{~B}(€ 38.50, € 1.00)$, if scenario 2

$\mathrm{A}(€ 100.00, € 80.00) \& \mathrm{~B}(€ 192.50, € 5.00)$, if scenario 3

\subsection{Measuring time preferences: Laury et al. (2012)}

In Laury et al. (2012)'s discount rate task, subjects are shown 20 paired choices between two options. In Option A, subjects could earn money in 3 weeks with a fixed probability of 50\%. In option B, there was the chance to earn the same amount of money but within 12 weeks. However, the success probability in option B was systematically raised from $50 \%$ to $64.7 \%$. Due to the different time delay, option A is denoted as "sooner option" and option B as "later option". The more often subjects select A ("number of sooner choices"), the more impatient they are. Impatience is measured in terms of the number of sooner A-choices. 
Table 2: Discount rate elicitation task choices and implied discount rate range (Scenario 1)

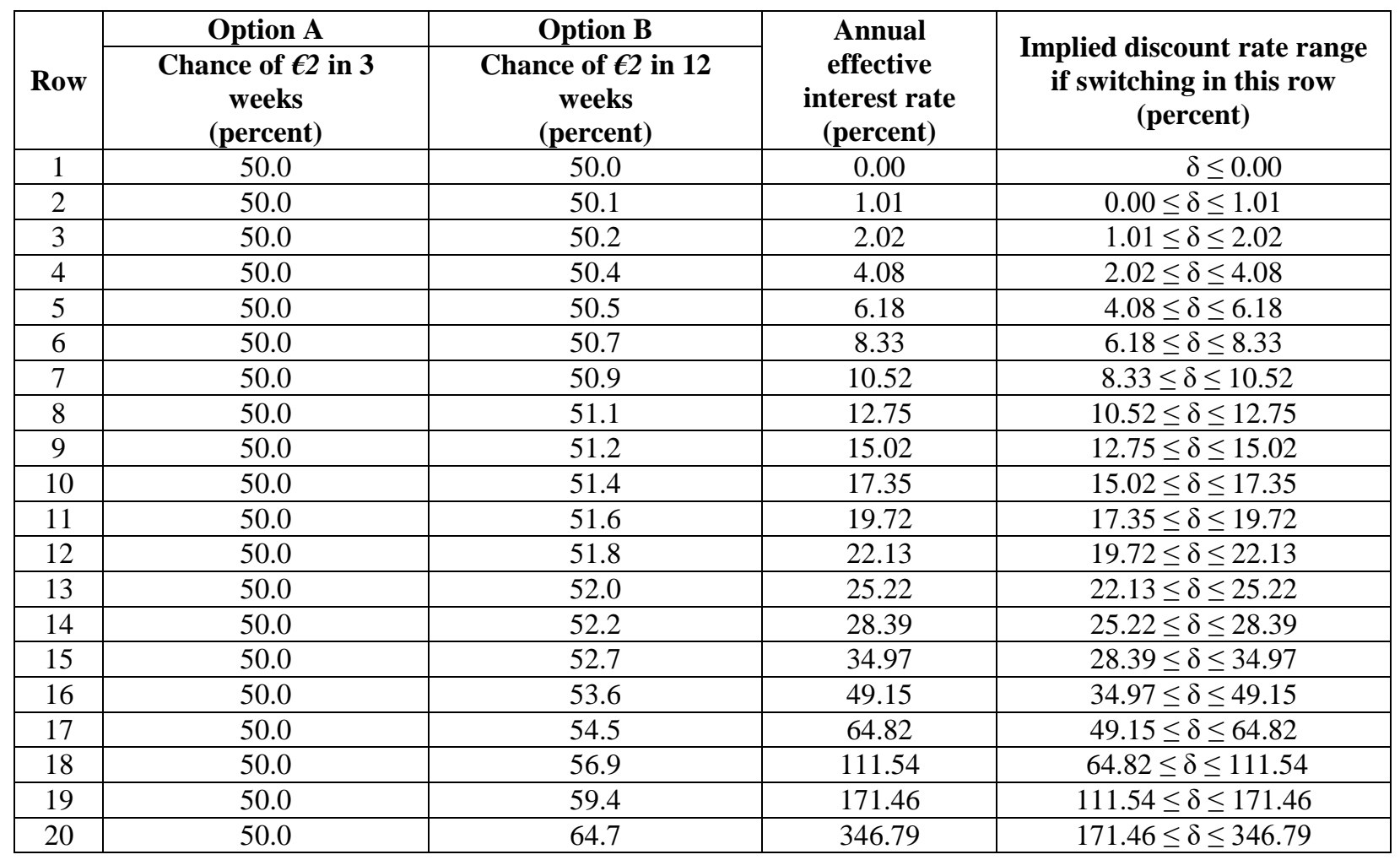

(a) The last two columns were not shown to the subjects.

Subjects could earn ...

\section{$€ 2$ in scenario 1 \\ $€ 20$ in scenario 2 \\ $€ 200$ in scenario 3}

\subsection{Measuring cognitive abilities: Cognitive reflection test (CRT)}

To measure cognitive abilities, we resort to the cognitive reflection test. Subjects are presented a total of 7 questions (cf., Table 3). Broadly speaking, intuitive thinking leads to the wrong answer, whereas a second look at the exercise often helps to find the correct answer. For example, item 4 reads "If you're running a race and you pass the person in second place, what place are you in?" The intuitive answer is "first": if someone passes the person in second place, then someone "must" be first. However, this intuition is wrong. The correct answer is "two": passing the person in second, then you are yourself second. The individual cognitive ability is measured by adding up the correctly answered question items. It can take values from 0 to 7. 
Table 3: Cognitive reflection test: Question items and correct answers ${ }^{\text {(a) }}$

\begin{tabular}{|l|l|c|l|}
\hline & Question & $\begin{array}{c}\text { Correct } \\
\text { answer }\end{array}$ & Source \\
\hline 1 & $\begin{array}{l}\text { If it takes 5 machines 5 minutes to make 5 widgets, how long would it } \\
\text { take } 100 \text { machines to make 100 widgets?_minutes }\end{array}$ & 5 & Frederick (2005) \\
\hline 2 & $\begin{array}{l}\text { Soup and salad cost } € 5.50 \text { in total. The soup costs a euro more than the } \\
\text { salad. How much does the salad cost? }\end{array}$ & 2.25 & Baron et al. (2015) \\
\hline 3 & $\begin{array}{l}\text { In a lake, there is a patch of lily pads. Every day, the patch doubles in } \\
\text { size. If it takes 48 days for the patch to cover the entire lake, how long } \\
\text { would it take for the patch to cover half of the lake?_ days }\end{array}$ & 47 & Frederick (2005) \\
\hline 4 & $\begin{array}{l}\text { If you're running a race and you pass the person in second place, what } \\
\text { place are you in? }\end{array}$ & 8 & $\begin{array}{l}\text { Thomson } \\
\text { Oppenheimer (2016) }\end{array}$ \\
\hline 5 & $\begin{array}{l}\text { A farmer had 15 sheep and all but 8 died. How many are left? } \\
\text { Ond }\end{array}$ \\
\hline 6 & $\begin{array}{l}\text { Emily's father has three daughters. The first two are named April and } \\
\text { May. What is the third daughter's name? }\end{array}$ & Emily & $\begin{array}{l}\text { Thomson and } \\
\text { Oppenheimer (2016) }\end{array}$ \\
\hline 7 & $\begin{array}{l}\text { How many cubic feet of dirt are there in a hole that is 10 cm deep x 20 } \\
\text { cm wide x 10 cm long? }\end{array}$ & 0 & $\begin{array}{l}\text { Thomson and } \\
\text { Oppenheimer (2016) }\end{array}$ \\
\hline
\end{tabular}

(a) The last two columns (solution and reference) were not shown to the subjects.

For each question correctly answered, subjects received ...

E0.10 in scenario 1

$€ 0.50$ in scenario 2

€3 in scenario 3.

\section{Recruitment and description of the experimental subjects}

\subsection{Recruitment}

Overall, we deal with two convenience samples (agricultural students and farmers). The recruitment of the agricultural students was systematic and straightforward. Starting point was a website (www.agrarstudieren.de/universitaeten/), which lists 10 German universities where people can study agricultural economics. To obtain a wide range of subjects, the following people/institutions of each university listed have been contacted with the plea to advertise the study: the dean of the faculty of agricultural sciences, a professor from the agricultural department, and the student council for agricultural sciences. We originally intended to recruit farmers via a survey company to get a quota representative sample of the population in Germany with regard to age, gender, and region. Due to the low number of registered farmers, this was unfortunately not 
successful, and farmers had to be hand-selected, which turned out to be a somewhat tedious procedure. We contacted the heads/presidents of the 18 regional farmers' associations of Federal Republic of Germany (Landesbauernverbände) and its district councils (Landwirtschaftliche Kreisverbände) as well as the executive board of the Initiative for Domestic Agriculture (Initiative Heimische Landwirtschaft) with the request to make their members familiar with our study. Moreover, the freely available contact data of the agricultural training companies (Landwirtschaftliche Ausbildungsbetriebe) were used to contact these farmers and advertise the study.

\subsection{Description of the subjects}

A total of 150 agricultural students and 150 farmers attended our Internet-based study during the period 14.9.2020-13.11.2020. There are considerable differences in gender between the two populations. Of the farmers, $84 \%$ indicated themselves as male and only $16 \%$ female. In contrast, $74 \%$ of the students were female and only $25.33 \%$ male. One agricultural student $(0.67 \%)$ indicated to be "other." As expected, the farmers were on average older $(\mathrm{m}=40.86$ years, $\mathrm{sd}=11.79$, $\mathrm{min}=18$, $\max =70)$ than the students $(m=23.20$ years, $s d=3.28, \min =18, \max =33)$. Further variables were collected and shall be mentioned here to get a more detailed impression about possible similarities and differences of both populations. Subjects were asked whether they are member of a church or a religious community. A total of $59.33 \%$ of the agricultural students and $82.26 \%$ of the farmers indicated to do so. Subjects were asked how satisfied they are, all in all, with their life at present on an 11-item scale ( $0=$ "completely dissatisfied" and $10=$ "completely satisfied"). On average, students $(\mathrm{m}=7.21, \mathrm{sd}=2.29)$ indicated to be somewhat happier than farmers $(\mathrm{m}=6.78, \mathrm{sd}=2.12)$. Moreover, subjects were asked about their political attitude on a scale from very left $(=0)$ to very right $(=10)$. Students $(\mathrm{m}=3.54, \mathrm{sd}=1.59)$ were on average more left-oriented than farmers $(\mathrm{m}=5.64$, $\mathrm{sd}=1.72)$.

\section{Experimental findings ${ }^{2}$}

\subsection{Behaviors in the respective experiments}

On average, the experimental subjects can be described as risk averse. For both populations (students and farmers), risk aversion is least pronounced in the lowest monetary incentive level (scenario 1; cf., Table 4). Somewhat surprisingly, we do not find the highest level of risk aversion in the scenario with the highest monetary incentives. This contradicts previous findings that report evidence of a stake size effect (i.e, the positive relationship between monetary incentives and risk aversion; Holt and Laury 2002, Holt and Laury 2005). Cohens'd indicates that both populations

\footnotetext{
${ }^{2}$ The multiple price lists described above to elicit risk aversion and impatience rest on the axioms of rational choice. For example, people are assumed to be in line with transitivity (i.e., choices are internally consistent) and monotonicity (i.e., better outcomes are preferred with a higher than a lower probability). However, multiple price lists are prone to inconsistent choices (Andersen et al. 2006; Engel and Kirchkamp 2019). In the Holt and Laury (2002) procedure, subjects can inconsistently switch back and forth between A and B, or choose the dominated option A in the $10^{\text {th }}$ lottery pair. Similarly, inconsistent behaviors in Laury et al. (2012) comprises multiple switching between option A and option B. Moreover, opting for option B instead of option A in the first row (same probability to win the prize, but 9 weeks more waiting time associated with option B) could be interpreted as inconsistent unless subjects are indifferent between waiting and not waiting. Many studies ignore inconsistent subjects as long the fraction is relatively small (Holt and Laury 2002). In contrast, a large fraction of inconsistent subjects can distort the results, and as a consequence are mostly dropped out of the sample (but in a later step often subject of analysis; Jacobson and Petrie 2009; Hirschauer et al. 2013). We observe a low rate of inconsistent choices and followed the practice to keep these subjects in the sample: Only $10 \%$ (more precisely, $8 \%$ of the students and $12 \%$ of the farmers) of the subjects behave inconsistently in the Holt and Laury procedure. Even less inconsistent choices were made in the procedure of Laury et al. (2012) to elicit impatience (5.33\% of the subjects behave inconsistently). No differences of the population could be found.
} 
are very similar in the risk elicitation task. The individuals' discount rate (i.e., impatience) varies considerably with the subject pool and level of monetary incentive. The level of impatience is much higher in the low-incentive scenario 1 than in the high-incentive scenario 3. Maybe subjects value waiting more when there are considerable stakes. Moreover, Cohen's d shows that farmers are more impatient than students across all incentive levels. In contrast, cognitive ability seems to be unrelated to the level of monetary incentives and subject pool. This finding is partly in line with the meta-study of Brañas-Garza et al. (2019), who find that monetary incentives do not influence the performance much but also that students perform better than non-students. The latter is similar to the finding of Belot et al. (2015), who argue that non-students on average have a higher cognitive ability score. However, in our study there are no differences between the populations.

Table 4: Cross-comparisons of risk preferences, time preferences, and cognitive abilities ${ }^{(1)}$

\begin{tabular}{|l|c|c|c|c|c|c|}
\hline $\begin{array}{l}\text { Between subject pools: } \\
\text { students vs farmers }\end{array}$ & \multicolumn{2}{|c|}{ Mean } & \multicolumn{2}{c|}{ Std. Dev. } & Welch's t-test ${ }^{(2)}$ & Cohen's d \\
\hline Risk aversion & & & & & & \\
\hline Students 1 vs farmers 1 & 4.84 & 5.02 & 1.8223 & 1.8223 & 0.6289 & 0.0969 \\
\hline Students 2 vs farmers 2 & 5.90 & 5.90 & 1.8433 & 1.9192 & 1.0000 & 0 \\
\hline Students 3 vs farmers 3 & 5.74 & 5.62 & 1.9671 & 2.3025 & 0.7799 & 0.0560 \\
\hline Impatience & & & & & & \\
\hline Students 1 vs farmers 1 & 7.56 & 11.52 & 6.9109 & 6.5907 & 0.0042 & 0.5864 \\
\hline Students 2 vs farmers 2 & 8.14 & 10.22 & 6.8333 & 6.5099 & 0.1223 & 0.3116 \\
\hline Students 3 vs farmers 3 & 4.92 & 8.98 & 6.1106 & 7.3968 & 0.0035 & 0.5984 \\
\hline Cognitive ability & & & & & & 0.1189 \\
\hline Students 1 vs farmers 1 & 5.78 & 5.32 & 1.3745 & 1.5444 & 0.6305 & 0.0965 \\
\hline Students 2 vs farmers 2 & 5.58 & 5.72 & 1.5790 & 1.3099 & 0.9415 & 0.0147 \\
\hline Students 3 vs farmers 3 & 5.76 & 5.74 & 1.2707 & 1.4400 & \\
\hline
\end{tabular}

(1) Numbers in column 1 indicate the respective scenario ( $1=$ low incentives, $2=$ medium incentives, $3=$ relatively high incentives)

(2) This t-test mitigates the assumption of variance homogeneity.

\subsection{Relevance of cognitive ability in explaining risk aversion and impatience}

Pearson's correlation coefficient indicates a low association between cognitive ability and risk aversion ( $\mathrm{r}=-0.093 ; 95 \% \mathrm{CI}$ : -0.205 to 0.020$)$ as well as between cognitive ability and impatience ( $\mathrm{r}=-0.013$; 95\% CI: -0.126 to 0.100). The signs are the same as in Dohmen et al. (2010), but the strength of the correlation is considerably smaller in our study. Furthermore, we use one-way ANOVA to analyze whether agricultural students as well as farmers can be assumed to have equal mean risk aversion and impatience independent of their cognitive ability score in the respective scenarios. Even if multiple testing is not controlled for, all p-values (and most of them considerably) are $>0.05$, which provides further evidence that the associations of interest are rather low (cf., Appendix 1). In a regression analysis, we now want to explain the dependent variables risk aversion and impatience with the help of cognitive ability and some control variables. Simple ordinary least squares (OLS) linear regressions are carried out. Robust standard errors are provided because there is evidence of violation of the homoscedasticity assumption (cf., Appendix 2).

The key variable of the regression analysis in Table 5 is "CRT-score", which denotes the cognitive ability of the experimental subjects. It is negative in all four specifications. However, the magnitude of the association is not only small (in columns I and II) or near zero (in columns III and IV), but the p-values are very large, too. Note that, as Altman and Bland (1995) remarked, large p-values 
should not be interpreted in a sense that we find no effect ("absence of evidence is not evidence of absence"). But the effect size indicates that cognitive ability is of minor relevance to explain risk aversion and impatience, respectively. More important determinants to explain risk aversion and impatience are the scenario, where the subjects have been assigned to, and, in case of impatience, the population. Life satisfaction seems the matter to explain impatience, which is, however, beyond the scope of this paper.

Table 5: Regressions to explain risk aversion and impatience

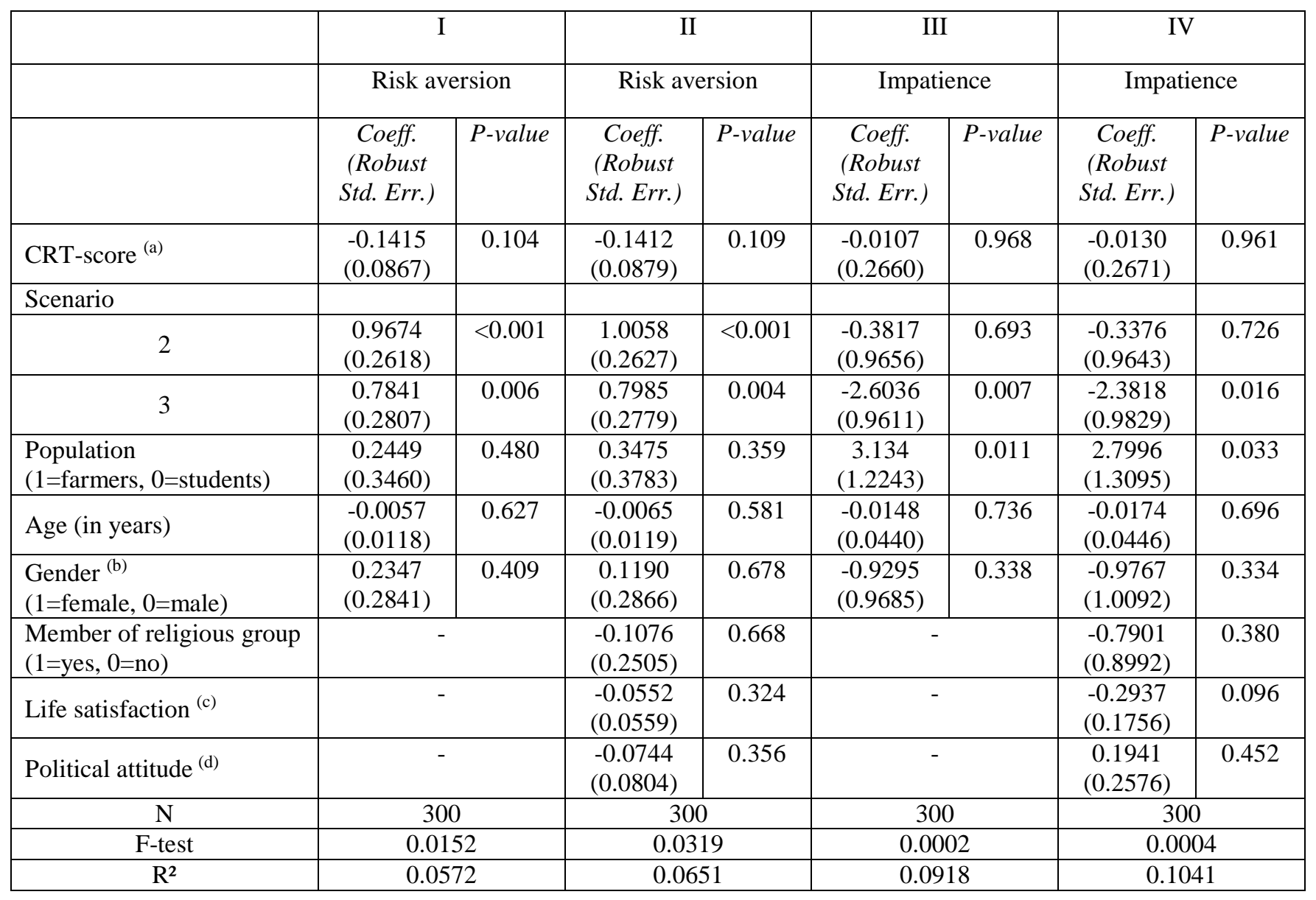

(a) Range of the score 0 to 7, with low values reflecting intuitive thinking and high values being associated with reflective thinking (b) There was one subject associating with the third gender ( $2=$ other). We do not provide further information on this subject because it is rather meaningless due to the low sample size.

(c) $0=$ completely dissatisfied to $10=$ completely satisfied

(d) $0=$ very left to $10=$ very right

\section{Concluding remarks}

Inspired by Dohmen et al. (2010), the goal of this paper was to re-analyze with new data whether risk aversion and impatience are related to cognitive ability. For this purpose, an experimental study was conducted with two populations and three different incentive levels. Overall, we find that risk aversion and impatience are negatively correlated with cognitive ability. However, the strength of evidence is negligibly small. Given the assumption that the results of this paper are robust, it indicates that no control for cognitive ability would be needed if someone is interested in 
the associations between risk aversion and impatience to real-world phenomena. However, science is cumulative and further research is necessary to overcome several limitations of the study. First of all, the research at present tackled correlations but not causal effects. Second, the study dealt with agricultural students and farmers. Further research must show, whether the findings can be replicated to other subject pools. Third, risk aversion, impatience, and cognitive ability are latent constructs that must be measured. However, different instruments might come to different findings which, in turn, mitigate the external validity of the findings.

\section{Acknowledgment}

The financial support of the Deutsche Forschungsgemeinschaft (DFG, German Research Foundation - 388911356) is gratefully acknowledged.

\section{References}

Altman, D.G., Bland, J.M. (1995): Absence of evidence is not evidence of absence. British Medical Journal 311(7003): 485.

Andersen, S., Harrison, G.W., Lau, M.I., Rutström, E.E. (2006): Elicitation using multiple price list formats. Experimental Economics 9: 383-405.

Asravor, R.K. (2019): Farmers' risk preference and the adoption of risk management strategies in Northern Ghana. Journal of Environmental Planning and Management 62(5): 881-900.

Baron, J., Scott, S., Fincher, K., Metz, S. (2015). Why does the Cognitive Reflection Test (sometimes) predict utilitarian moral judgment (and other things)? Journal of Applied Research in Memory and Cognition 4(3): 265-284.

Bosch-Rosa, C., Meissner, T., Bosch-Domènech, A. (2018): Cognitive bubbles. Experimental Economics 21: 132-153.

Brañas-Garza, P., Kujal, P., Lenkei, B. (2019): Cognitive reflection test: Whom, how, when. Journal of Behavioral and Experimental Economics 82: 101455.

Christensen, G., Miguel, E. (2018): Transparency, Reproducibility, and the Credibility of Economics Research. Journal of Economic Literature 56(3): 920-80.

Dalhaus, T., Musshoff, O., Finger, R. (2018): Phenology Information Contributes to Reduce Temporal Basis Risk in Agricultural Weather Index Insurance. Scientific Reports 8(46): doi.org/10.1038/s41598017-18656-5.

Di Falco, S., Berck, P., Bezabih, M., Köhlin, G. (2019): Rain and impatience: Evidence from rural Ethiopia. Journal of Economic Behavior \& Organization 160: 40-51.

D’Acunto, F., Hoang, D., Paloviita, M., Weber, M. (2019): Cognitive Abilities and Inflation Expectations. AEA Papers and Proceedings 109: 562-566.

Dohmen, T., Falk, A., Huffman, D., Sunde, U. (2010): Are Risk Aversion and Impatience Related to Cognitive Ability? American Economic Review 100(3): 1238-1260. 
Dohmen, T., Falk, A., Huffman, D., Sunde, U. (2018): On the Relationship between Cognitive Ability and Risk Preference. Journal of Economic Perspectives 32(2): 115-134.

Dreber, A., Johannesson, M. (2019): Statistical Significance and the Replication Crisis in the Social Sciences. Oxford Research Encyclopedia of Economics and Finance: https://oxfordre.com/economics/view/10.1093/acrefore/9780190625979.001.0001/acrefore9780190625979-e-461.

Engel, C., Kirchkamp, O. (2019): How to deal with inconsistent choices on multiple price lists. Journal of Economic Behavior \& Organization 160: 138-157.

Falk, A., Becker, A., Dohmen, T., Enke, B., Huffman, D., Sunde, U. (2018): Global Evidence on Economic Preferences. The Quarterly Journal of Economics 133(4): 1645-1692.

Frey, B. (1997): Not Just For the Money-An Economic Theory of Personal Motivation. Cheltenham: Edward Elgar Publishing.

Fréchette, G.R. (2015): Laboratory Experiments: Professionals versus Students. Fréchette, G.R. and Schotter, A. (Eds.): Handbook of Experimental Economic Methodology. Oxford University Press, Oxford: 360-390.

Frederick, S. (2005): Cognitive Reflection and Decision Making. Journal of Economic Perspectives 19(4): $25-42$.

Guala, F. (2005): The Methodology of Experimental Economics. Cambridge: Cambridge University Press.

Gurven, M., Fuerstenberg, E., Trumble, B., Stieglitz, J., Beheim, B., Davis, H., \& Kaplan, H. (2017): Cognitive performance across the life course of Bolivian forager-farmers with limited schooling. Developmental Psychology 53(1): 160-176.

Hermann, D., Musshoff, O. (2016): Measuring time preferences: Comparing methods and evaluating the magnitude effect. Journal of Behavioral and Experimental Economics 65: 16-26.

Holt, C.A., Laury, S.K., 2002. Risk aversion and incentive effects. American Economic Review 92 (5), 1644-1655.

Holt, C.A., Laury, S.K. (2005): Risk Aversion and Incentive Effects: New Data without Order Effects. American Economic Review 95(3): 902-912.

Henrich, J., Heine, S.J., Norenzayan, A. (2010): The Weirdest People in the World? Behavioral and Brain Sciences 33(2-3): 61-83.

Hirschauer, N., Musshoff, O., Maart-Noelck, S. C., \& Gruener, S. (2013). Eliciting risk attitudes - how to avoid mean and variance bias in Holt-and-Laury lotteries. Applied Economics Letters 21(1): 35-38.

Jacobson, S., Petrie, R. (2009): Learning from mistakes: What do inconsistent choices over risk tell us? Journal of Risk and Uncertainty 38: 143-158.

Passolunghi, M.C., Lanfranchi, S., Altoè, G., Sollazzo, N. (2015): Early numerical abilities and cognitive skills in kindergarten children. Journal of Experimental Child Psychology 135: 25-42.

Salahodjaev, R. (2018): Is there a link between cognitive abilities and environmental awareness? Crossnational evidence. Environmental Research 166: 86-90. 
Oechssler, J., Roider, A., Schmitz, P.W. (2009): Cognitive abilities and behavioral biases. Journal of Economic Behavior \& Organization 72(1): 147-152.

Thomson, K.S., Oppenheimer, D.M. (2016): Investigating an alternate form of the cognitive reflection test. Judgment and Decision Making 11(1): 99-113. 


\section{Appendix 1: ANOVA}

Table A1: Analysis of Variance (ANOVA)

\begin{tabular}{|c|c|c|c|c|}
\hline Null hypothesis $^{(\mathbf{a})}$ & Population & Scenario & $\mathbf{F}$ & P-Value \\
\hline Risk aversion identical & Students & 1 & 0.92 & 0.4767 \\
\hline Risk aversion identical & Students & 2 & 1.33 & 0.2663 \\
\hline Risk aversion identical & Students & 3 & 0.63 & 0.6814 \\
\hline Risk aversion identical & Farmers & 1 & 2.28 & 0.0627 \\
\hline Risk aversion identical & Farmers & 2 & 0.70 & 0.5992 \\
\hline Risk aversion identical & Farmers & 3 & 0.48 & 0.7909 \\
\hline Risk aversion identical & Both & 1 & 0.93 & 0.4743 \\
\hline Risk aversion identical & Both & 2 & 0.95 & 0.4655 \\
\hline Risk aversion identical & Both & 3 & 0.39 & 0.8546 \\
\hline Impatience identical & Students & 1 & 0.66 & 0.6538 \\
\hline Impatience identical & Students & 2 & 0.66 & 0.6792 \\
\hline Impatience identical & Students & 3 & 1.38 & 0.2497 \\
\hline Impatience identical & Farmers & 1 & 0.81 & 0.5486 \\
\hline Impatience identical & Farmers & 2 & 1.05 & 0.3921 \\
\hline Impatience identical & Farmers & 3 & 1.89 & 0.1162 \\
\hline Impatience identical & Both & 1 & 0.76 & 0.6009 \\
\hline Impatience identical & Both & 2 & 0.83 & 0.5502 \\
\hline Impatience identical & Both & 3 & 1.59 & 0.1700 \\
\hline
\end{tabular}

(a) H0: No difference in means across the levels of cognitive abilities.

\section{Appendix 2: Test on heteroscedasticity}

Table A2: Test on heteroscedasticity after OLS-Regressions

\begin{tabular}{|c|c|c|c|}
\hline & Ho & Breusch-Pagan / Cook- \\
Weisberg test & White's test \\
\hline 1 & Constant variance / homoscedasticity & 0.1288 & 0.0757 \\
\hline 2 & I & 0.0958 & 0.0084 \\
\hline 3 & II & 0.5635 & 0.2392 \\
\hline 4 & III & 0.6563 & 0.7132 \\
\hline
\end{tabular}




\section{Supplementary}

Figure S1: Link of cognitive ability to risk aversion and impatience

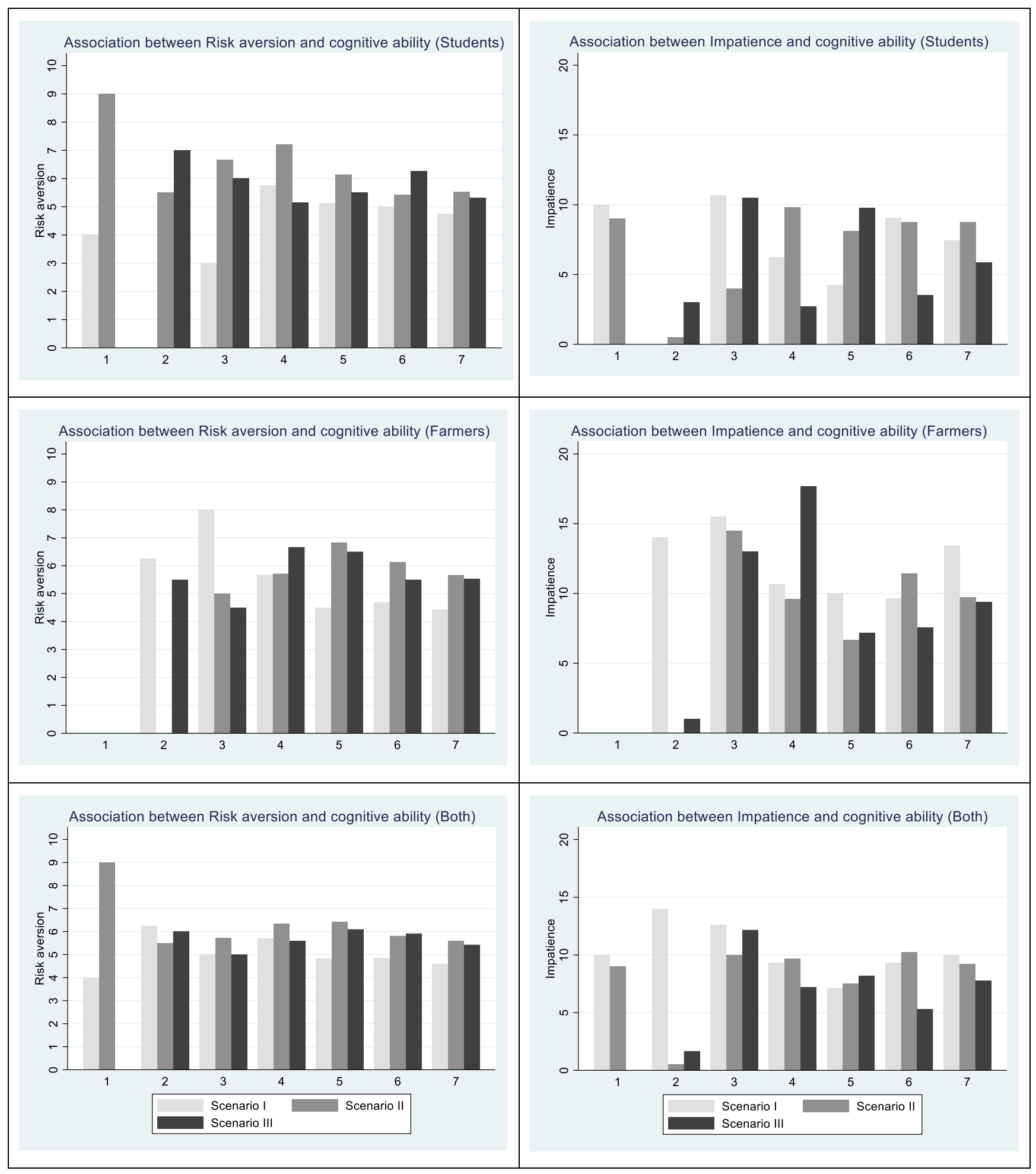


Table 6: Cross-comparisons of risk preferences, time preferences, and cognitive abilities ${ }^{(1)}$

\begin{tabular}{|c|c|c|c|c|c|c|}
\hline \multirow{2}{*}{$\begin{array}{l}\begin{array}{l}\text { Between subject pools: } \\
\text { students vs farmers }\end{array} \\
\text { Risk aversion }\end{array}$} & \multicolumn{2}{|c|}{ Mean } & \multicolumn{2}{|c|}{ Std. Dev. } & \multirow[t]{2}{*}{ Welch's t-test } & \multirow[t]{2}{*}{ Cohen's d } \\
\hline & & & & & & \\
\hline Students 1 vs farmers 1 & 4.84 & 5.02 & 1.8223 & 1.8223 & 0.6289 & 0.0969 \\
\hline Students 2 vs farmers 2 & 5.90 & 5.90 & 1.8433 & 1.9192 & 1.0000 & 0 \\
\hline Students 3 vs farmers 3 & 5.74 & 5.62 & 1.9671 & 2.3025 & 0.7799 & 0.0560 \\
\hline \multicolumn{7}{|l|}{ Impatience } \\
\hline Students 1 vs farmers 1 & 7.56 & 11.52 & 6.9109 & 6.5907 & 0.0042 & 0.5864 \\
\hline Students 2 vs farmers 2 & 8.14 & 10.22 & 6.8333 & 6.5099 & 0.1223 & 0.3116 \\
\hline Students 3 vs farmers 3 & 4.92 & 8.98 & 6.1106 & 7.3968 & 0.0035 & 0.5984 \\
\hline \multicolumn{7}{|l|}{ Cognitive ability } \\
\hline Students 1 vs farmers 1 & 5.78 & 5.32 & 1.3745 & 1.5444 & 0.1189 & 0.3146 \\
\hline Students 2 vs farmers 2 & 5.58 & 5.72 & 1.5790 & 1.3099 & 0.6305 & 0.0965 \\
\hline Students 3 vs farmers 3 & 5.76 & 5.74 & 1.2707 & 1.4400 & 0.9415 & 0.0147 \\
\hline \multicolumn{7}{|l|}{$\begin{array}{l}\text { Within subject pool: } \\
\text { agricultural students }\end{array}$} \\
\hline \multicolumn{7}{|l|}{ Risk aversion } \\
\hline Students 1 vs Students 2 & 4.84 & 5.90 & 1.8223 & 1.8433 & 0.0047 & 0.5783 \\
\hline Students 1 vs Students 3 & 4.84 & 5.74 & 1.8223 & 1.9671 & 0.0196 & 0.4746 \\
\hline Students 2 vs Students 3 & 5.9 & 5.74 & 1.8433 & 1.9671 & 0.6756 & 0.0839 \\
\hline \multicolumn{7}{|l|}{ Impatience } \\
\hline Students 1 vs Students 2 & 7.56 & 8.14 & 6.9109 & 6.8333 & 0.6739 & 0.0843 \\
\hline Students 1 vs Students 3 & 7.56 & 4.92 & 6.9109 & 6.1106 & 0.0457 & 0.4047 \\
\hline Students 2 vs Students 3 & 8.14 & 4.92 & 6.8333 & 6.1106 & 0.0147 & 0.4967 \\
\hline \multicolumn{7}{|l|}{ Cognitive ability } \\
\hline Students 1 vs Students 2 & 5.78 & 5.58 & 1.3745 & 1.5790 & 0.5009 & 0.1351 \\
\hline Students 1 vs Students 3 & 5.78 & 5.76 & 1.3745 & 1.2707 & 0.9399 & 0.0151 \\
\hline Students 2 vs Students 3 & 5.58 & 5.76 & 1.5790 & 1.2707 & 0.5315 & 0.1255 \\
\hline \multicolumn{7}{|l|}{$\begin{array}{l}\text { Within subject pool: } \\
\text { farmers }\end{array}$} \\
\hline \multicolumn{7}{|l|}{ Risk aversion } \\
\hline Farmers 1 vs Farmers 2 & 5.02 & 5.9 & 1.8897 & 1.9192 & 0.0229 & 0.4620 \\
\hline Farmers 1 vs Farmers 3 & 5.02 & 5.62 & 1.8897 & 2.3025 & 0.1576 & 0.2848 \\
\hline Farmers 2 vs Farmers 3 & 5.9 & 5.62 & 1.9192 & 2.3025 & 0.5105 & 0.1321 \\
\hline \multicolumn{7}{|l|}{ Impatience } \\
\hline Farmers 1 vs Farmers 2 & 11.52 & 10.22 & 6.5907 & 6.5099 & 0.3234 & 0.1984 \\
\hline Farmers 1 vs Farmers 3 & 11.52 & 8.98 & 6.5907 & 7.3968 & 0.0729 & 0.3625 \\
\hline Farmers 2 vs Farmers 3 & 10.22 & 8.98 & 6.5099 & 7.3968 & 0.3757 & 0.1779 \\
\hline \multicolumn{7}{|l|}{ Cognitive ability } \\
\hline Farmers 1 vs Farmers 2 & 5.32 & 5.72 & 1.5444 & 1.3099 & 0.1657 & 0.2793 \\
\hline Farmers 1 vs Farmers 3 & 5.32 & 5.74 & 1.5444 & 1.4400 & 0.1627 & 0.2812 \\
\hline Farmers 2 vs Farmers 3 & 5.72 & 5.74 & 1.3099 & 1.4400 & 0.9422 & 0.0145 \\
\hline
\end{tabular}

(1) Numbers in the first column indicate the respective scenario (1=low incentives, $2=$ medium incentives, $3=$ relatively high incentives) 